\title{
Should magnesium be routine for arrhythmia prevention?
}

\author{
Steven M. Schwartz, MD, MS, FRCPC, FAHA
}

From the Departments of Paediatrics and Critical Care Medicine, Divisions of Cardiac Critical Care Medicine and Cardiology, The Hospital for Sick Children and The University of Toronto, Toronto, Ontario.

Disclosures: Author has nothing to disclose with regard to commercial support.

Received for publication April 26, 2018; accepted for publication April 26, 2018; available ahead of print June 5, 2018.

Address for reprints: Steven M. Schwartz, MD, MS, FRCPC, FAHA, Department of Critical Care Medicine, The Hospital for Sick Children, 555 University Ave, Toronto, ON M5G 1X8, Canada (E-mail: steven.schwartz@ sickkids.ca).

J Thorac Cardiovasc Surg 2018;156:762

$0022-5223 / \$ 36.00$

Copyright $(c) 2018$ by The American Association for Thoracic Surgery

https://doi.org/10.1016/j.jtcvs.2018.04.111

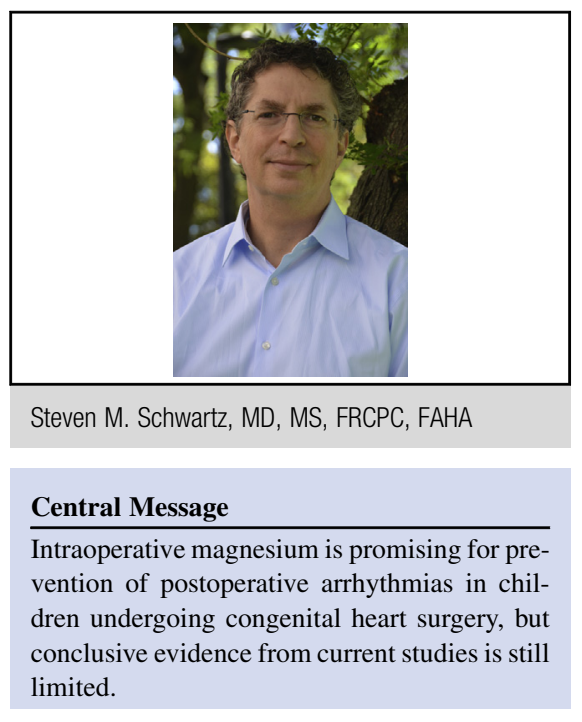

See Article page 763. appropriately treated in a timely fashion. As such, prevention seems a more attractive approach to achieve good outcomes, especially when the preventive measures in question are relatively simple and low risk. In the current issue of the Journal, He and colleagues ${ }^{1}$ describe such an intervention for the prevention of postoperative arrhythmias after congenital heart surgery. They used propensity matching to assess outcomes from a practice change at their institution in which magnesium, first at $25 \mathrm{mg} / \mathrm{kg}$ and later at $50 \mathrm{mg} / \mathrm{kg}$, was administered to patients at the time of aortic crossclamp release. Propensity matching was based on age, weight, Aristotle score, cardiac diagnosis, and surgical time, all of which have been shown in previous studies to have some relation to the occurrence of postoperative arrhythmias. Their findings are impressive; a reduction in arrhythmia risk of $50 \%$ with almost all arrhythmia types significantly lessened in the treatment groups compared with those who did not receive magnesium. Hospital outcomes are not reported. This work supports the findings of other studies, including a randomized trial of magnesium supplementation in children that was terminated because of a beneficial treatment effect that was seen after only 28 of a planned 100 subjects were enrolled. ${ }^{2}$

As is common in retrospective reports, the authors conclude by advocating for a randomized trial. It is reasonable to ask, do we really need one? The current study is not conclusive proof for magnesium use. A particularly concerning limitation is that use of inotropic agents was not accounted for in the propensity matching despite several studies that have identified greater use of inotropic support as being associated with various tachycardias. One study in

particular specifically identified milrinone as an independent risk factor for a variety of tachyarrhythmias in a cohort of 603 patients who underwent congenital heart surgery. ${ }^{3}$ Of course, it is always difficult to differentiate cause and effect in such associations, especially in retrospective studies. Arrhythmias tend to occur in sick patients or make patients sick, and sicker patients tend to be treated with more inotropic support. Even taking this limitation into account, however, it is also prudent to note that magnesium supplementation as described in the current study is both relatively easy and low risk. It would be reasonable to use magnesium to prevent arrhythmias after congenital heart surgery based on this potentially favorable risk-benefit ratio, and it is likely that more and more programs will adopt this approach, whereas others will wait for additional evidence. Rather than a randomized trial then, this might be an excellent subject for a registry-based study as programs choose to make their own determinations regarding the persuasiveness of this and other studies.

\section{References}

1. He D, Aggarwal N, Zurakowski D, Jonas RA, Berul CI, Hanumanthaiah S, et al Lower risk of postoperative arrhythmias in congenital heart surgery following in traoperative administration of magnesium. J Thorac Cardiovasc Surg. 2018;156: 763-70.

2. Dorman BH, Sade RM, Burnette JS, Wiles HB, Pinosky ML, Reeves ST, et al. Magnesium supplementation in the prevention of arrhythmias in pediatric patients undergoing surgery for congenital heart defects. Am Heart J. 2000;139:522-8.

3. Smith AH, Owen J, Borgman KY, Fish FA, Kannankeril PJ. Relation of milrinone after surgery for congenital heart disease to significant postoperative tachyarrhythmias. Am J Cardiol. 2011;108:1620-4. 